\title{
Exogenous Application of Platelet-Leukocyte Gel during Open Subacromial Decompression Contributes to Improved Patient Outcome
}

\author{
A Prospective Randomized Double-Blind Study \\ P.A. Everts ${ }^{a} \quad$ R.J.J. Devilee ${ }^{b} \quad$ C. Brown Mahoney ${ }^{e} \quad$ A. van Erp ${ }^{b}$ \\ C.J.M. Oosterbos $^{\text {b }}$ M. Stellenboom ${ }^{b} \quad$ J.T.A. Knape ${ }^{d} \quad$ A. van Zundert ${ }^{c}$ \\ Departments of a Peri-Operative Blood Management, ${ }^{b}$ Orthopedic Surgery-Traumatology and ${ }^{\mathrm{c}}$ Anesthesiology, \\ Catharina Hospital, Eindhoven, and d Department of Anesthesiology, University Medical Center,

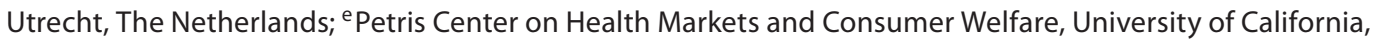 \\ Berkeley, Calif., USA
}

\section{Key Words \\ Growth factors · Open subacromial decompression • Pain • Platelet-leukocyte gel $\cdot$ Platelet-rich plasma $\cdot$ Range of motion}

\begin{abstract}
Background: Platelet-leukocyte gel (PLG) is being used during various surgical procedures in an attempt to enhance the healing process. We studied the effects of PLG on postoperative recovery of patients undergoing open subacromial decompression (OSD). Methods: PLG was produced from platelet-leukocyte-rich plasma (P-LRP), prepared from a unit of whole blood. Forty patients were included in the study. Self-assessed evaluations, using the American Shoulder and Elbow Surgeons scoring system of activities of daily living $(A D L)$, joint instability, pain levels, pain medications, and clinical evaluations for range of motion were conducted. $\boldsymbol{R} \boldsymbol{e}$ sults: Platelet and leukocyte counts were significantly increased in the P-LRP compared to baseline counts. Treated patients demonstrated decreased visual analog scales for pain and used significantly less pain medication, had an improved range of motion during passive forward elevation, external rotation, external rotation with arm at $90^{\circ}$ abduction, internal rotation, and cross body adduction compared
\end{abstract}

\section{KARGER \\ Fax +41613061234 \\ E-Mail karger@karger.ch}

www.karger.com
(C) 2008 S. Karger AG, Basel

Accessible online at:

www.karger.com/esr
$0014-312 \mathrm{X} / 08 / 0402-0203 \$ 24.50 / 0$ to control patients $(p<0.001)$. No differences in the instability score were observed between the groups. Furthermore, treated patients performed more ADL $(p<0.05)$. Conclusion: In the PLG-treated group, recovery was faster and patients returned earlier to daily activities and also took less pain medication than control subjects.

Copyright $\odot 2008$ S. Karger AG, Basel

\section{Introduction}

Open subacromial decompression (OSD) treatment for chronic impingement syndrome of the shoulder has been well documented [1-3]. The space between the acromion and humeral head is normally narrow and decreases with abduction of the arm. Any condition that further narrows this space can cause impingement of the shoulder top, the humeral head and the underlying soft tissue. Impingement can result from extrinsic compression or from rotator cuff insufficiency. Most common symptoms of shoulder impingement are pain, weakness and limitation in the range of motion.

During and after OSD surgery, the patients own defense mechanism is activated to reduce bleeding and initiate wound healing. Platelets play a pivotal role in this 
process through the formation of a platelet plug and activation of the blood coagulation cascade. Activated platelets at the wound site release several platelet growth factors, which initiate connective tissue healing and increase mitogenesis, angiogenesis, and macrophage migration $[4,5]$. At present, autologous platelet-leukocyte gel (PLG) can be prepared safely from the patient's own blood. A unit of whole blood, collected just prior to surgery, is centrifuged to obtain platelet-leukocyte-rich plas$\mathrm{ma}$ (P-LRP). The PLG is then formed by mixing P-LRP with a thrombin-calcium chloride preparation [6]. Treatment with PLG provides a source of concentrated platelets, with $\alpha$-granules that contain platelet-derived growth factor (PDGF) and transforming growth factor (TGF)- $\beta$. These growth factors augment the wound healing process $[7,8]$. The high concentration of non-activated leukocytes, present in the PLG, promotes anti-microbial activity at the wound site through destruction of bacteria and foreign materials and removal of damaged tissue [9, 10].

The success rate of an OSD depends on a rapid recovery of the shoulder function. Time to recovery can be improved through good wound healing and less postoperative pain. This is the first prospective randomized, double-blind study in which autologous PLG has been used during OSD. The purpose of this study was to evaluate the effect of PLG on surgical wound healing with emphasis on the restoration of range of motion, activities of daily living (ADL), pain and pain medication, as part of the treatment of the impingement syndrome (Neer grade II) using the American Shoulder and Elbow Surgeons (ASES) shoulder assessment method to evaluate the study objectives [11].

\section{Patients and Methods}

\section{Study Design}

The study was approved by the Institutional Ethics Committee of the Catharina Hospital, and a written informed consent was obtained from each patient according to the guidelines. Forty patients were prospectively entered into the study on the day of surgery.

\section{Patient Identifiers and Randomization Procedure}

Each patient received a unique patient identifier code. Formal randomization took place before the study started. Patients with patient codes corresponding to the drawn random numbers were assigned to the PLG treatment group, the other patients were assigned to the conventional treatment group. Investigators drew sealed envelopes with patient identifiers. Each envelope contained the randomization outcome for the identified patient. Study personnel opened the envelope within a time frame to guarantee that personnel were available to execute the PLG preparation and application procedure.

Patients were blinded with regard to which group they were randomized to prevent bias on answering pain sensation questions during the follow-up period and range of motion assessment. Randomization information was not put in the patients medical or nurse files.

The patients in the treatment group $(n=20)$ were injected with PLG, whereas the control group was not injected $(n=20)$. Patients were blinded with regard to which group they were randomized, to prevent bias when answering questions on pain sensation during the follow-up period.

\section{Patients}

The unique patient identifier codes enabled a reviewer to identify and compare the test results. The criteria for inclusion in the study were stage II impingement syndrome diagnosed more than 6 months preoperatively. Patients had a history of typical anterior pain during shoulder elevation, marked loss of active and passive shoulder motion, loss of range of motion, and an initial positive response to three subacromial infiltrations performed in a 6month period with a local anesthetic and corticoids (xylocaine and methylprednisolone). Standard magnetic resonance imaging was used in all patients to assess glenohumeral and acromioclavicular arthrosis, and measure subacromial calcifications. None of the patients had previous operative treatment. Furthermore, no patient showed evidence of a rotator cuff lesion on physical examination. However, if a rotator cuff lesion was observed during surgery, the patient was eliminated from the study. Exclusion criteria were a history of frozen shoulder, disorders of the acromioclavicular joint, degenerative arthritis of the glenohumeral joint, and calcifying tendonitis, shoulder instability, posttraumatic disorders, shoulder and elbow surgery, and hand disorders. None of the patients had accompanying diseases which would affect postoperative wound healing (e.g. diabetes), or were treated for acute shoulder dysfunction. The postoperative examinations were performed by an independent physician or nurse practitioner, blinded to the peri-operative treatment to prevent bias during the shoulder function testing. The ASES scoring method was applied to evaluate patients before and after surgery. The ASES scoring system is used to assess the outcome of patients after OSD, and produces scores equivalent to those obtained with the Constant and University of California at Los Angeles shoulder scales [12]. Furthermore, a psychometric analysis revealed that the ASES score is a reliable and valid responsive outcome tool [13].

\section{PLG Preparation Device}

PLG was prepared with the Magellan ${ }^{\mathrm{TM}}$ Autologous Platelet Separator System (MAPS; Medtronic, Minneapolis, Minn., USA). This device consists of a microprocessor-controlled centrifuge and two syringe pumps. One unit of blood is drawn from each patient, and is then pumped into the MAPS separation chamber. The blood sample is centrifuged at $1,200 \mathrm{~g}$, separating erythrocytes from the plasma. The low-density platelets separate and can be found between the red blood cells and the plasma. During centrifugation the syringe starts with the collection of the erythrocytes. When the light sensor in the MAPS detects the low-density platelets at the outer ends of the chamber, a second syringe collects the P-LRP. 


\section{PLG Preparation}

Blood for the PLG preparation was drawn after induction of anesthesia from all patients in the treatment group and the control group to guarantee patient blinding. In patients randomized to the PLG group, a total of $104 \mathrm{ml}$ of whole blood was slowly drawn in two $60-\mathrm{ml}$ syringes. Each syringe contained $52 \mathrm{ml}$ of blood and $8 \mathrm{ml}$ of the anticoagulant citrate dextrose solution-A to prevent clotting prior to the preparation of P-LRP. The MAPS was set to deliver $8 \mathrm{ml}$ of P-LRP after each cycle. A total volume of 16 $\mathrm{ml}$ of P-LRP was distributed into three aliquots: $0.5 \mathrm{ml}$ of P-LRP was used to determine platelet and leukocyte counts; $3.5 \mathrm{ml}$ of PLRP was used to prepare autologous thrombin for activating the P-LRP to produce PLG; the remaining $12 \mathrm{ml}$ of P-LRP was used to prepare PLG.

\section{Surgical Technique}

All patients were placed in the beach-chair position, and operated on by two surgeons well experienced in OSD surgery. OSD was performed via a $4-\mathrm{cm}$ shoulder strap skin incision, centered over the acromial clavicular joint. A deltoid splitting incision was made with electrocautery. The deltoid fibers were subperiostially released from the anterior acromion to facilitate exposure. A standard anterior acromioplasty was performed were the anterolateral and central portion of the subacromial bone were resected, using an oscillating saw. The decompression was completed when the acromion was considered flat. All osteophytes were removed from the undersurface. Prior to wound closure, the cuff was inspected for tears. The deltoid was re-attached with absorbable sutures. The subcutaneous layer was closed with an absorbable running suture and the skin was closed with a subcuticular suture. No drains were used in either patient group in order to avoid draining the PLG growth factors from the wound site.

Upon discharge, all patients had an arm sling for support of their operated arm. Postoperatively, all patients were treated according to a standard rehabilitation protocol, starting with active assisted range of motion on day 1 . As pain decreased, this progressed with strengthening exercises of the rotator cuff and shoulder muscles. Formal physical therapy, including standard pulley exercises, was started in the 2 nd postoperative week and continued until full range of motion returned. After achieving full range of motion, patients could either choose to continue physical therapy or begin a strengthening program at home.

\section{PLG Application}

In the PLG treatment group, a blunt 14-gauge needle was placed identically in all patients in the subacromial space during wound closure. After closure of the deltoid layer and the subcutaneous tissue, an intracapsular injection of $10 \mathrm{ml}$ of PLG was given. Before skin closure, an additional $3 \mathrm{ml}$ of PLG were injected under the subcutaneous layer covering the incision length. PLG was only given after the capsula and subcutaneous layers had been closed in order to avoid leakage of PLG outside the wound area (fig. 1).

\section{Outcome Assessment}

Data on the preoperative shoulder function were recorded. The ASES shoulder function assessment method is used to assess the ability to perform ADL, and includes a patient self-evaluation form and a physician assessment score to determine shoulder function including range of motion. The patient self-evaluation

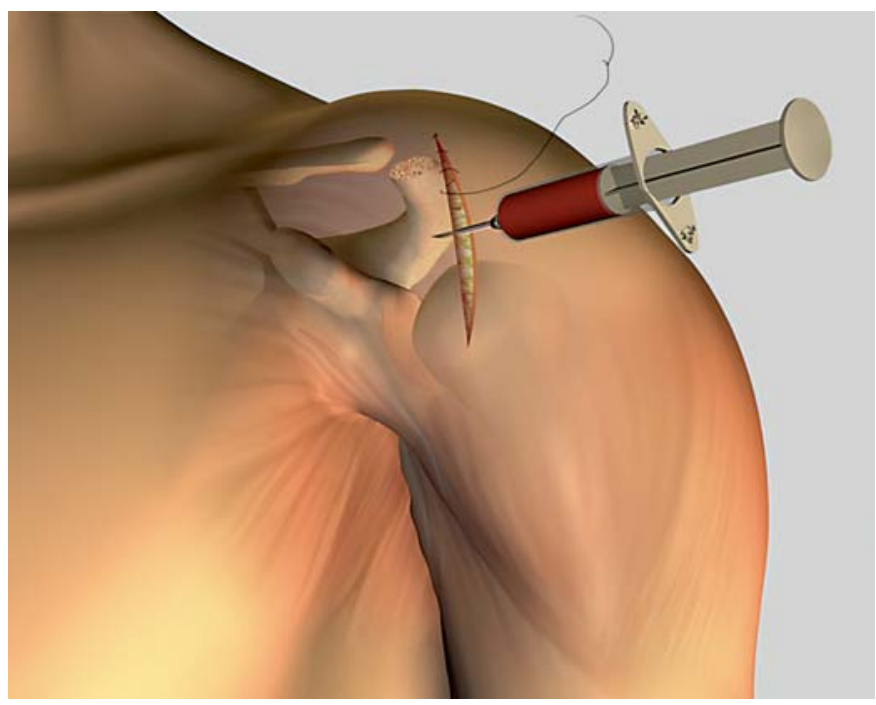

Fig. 1. Illustration of PLG application through the incision line following OSD. After closure of the deltoid layer and the subcutaneous tissue, an intracapsular injection of $10 \mathrm{ml}$ of PLG was given.

Table 1. Items in the ASES patient self-assessment scale for ADL

$\begin{aligned} 1 & \text { Put on a coat } \\ 2 & \text { Sleep on painful or affected side } \\ 3 & \text { Wash back } \\ 4 & \text { Manage toileting } \\ 5 & \text { Comb hair } \\ 6 & \text { Reach a high self } \\ 7 & \text { Lift } 5 \text { kg above affected shoulder } \\ 8 & \text { Throw a ball overhand with affected shoulder } \\ 9 & \text { Do usual work } \\ 10 & \text { Do usual sport }\end{aligned}$

Scores for items are: $0=$ Unable to do; $1=$ very difficult to do; 2 = somewhat difficult; 3 = not difficult.

section contained visual analog scales for pain (VAS) on a tenpoint scale. Ten ADL were assessed on a four-point ordinal scale. Patients were requested to keep a journal from the 1st postoperative week until 6 weeks after surgery to subjectively score symptoms, function, and ADL. Pain medication, instability, and an ADL questionnaire (table 1) were completed in the absence of a physician. Pain medication was recorded as either regular (e.g. aspirin or ibuprofen) or strong (e.g. codeine or naproxen). The shoulder index score (SIS) was calculated from data obtained from the ADL form and VAS assessment. Time to recovery of shoulder function was assessed with the interval until resumption of work, time until improvement in symptoms and ADL. The improvement in range of motion was assessed by an investigator who was blinded to the treatment given. A goniometer was used 


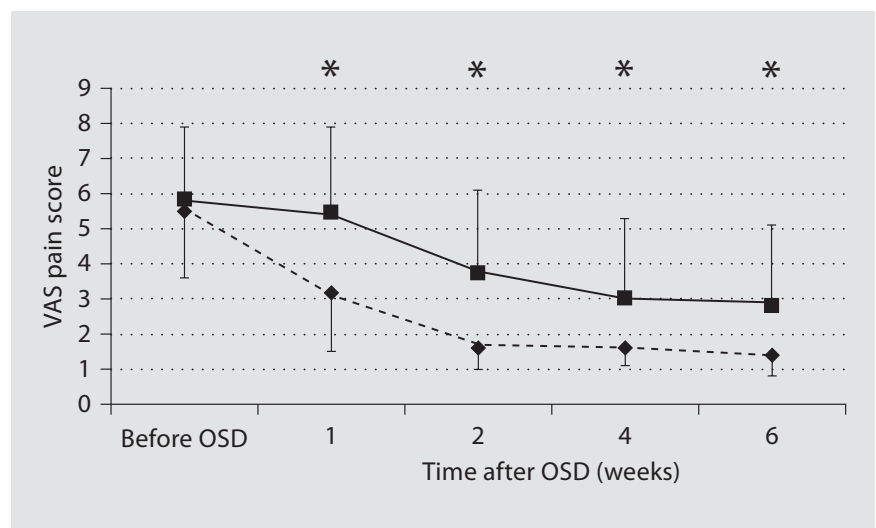

Fig. 2. VAS pain score until 6 weeks postoperatively for the control $(-)$ and PLG-treated patients $(---) .{ }^{*} \mathrm{p}<0.001 \mathrm{vs}$. the control group.

Table 2. Characteristics of the patients treated with OSD

\begin{tabular}{lcl}
\hline Characteristics & $\begin{array}{l}\text { Control } \\
(\mathrm{n}=20)\end{array}$ & $\begin{array}{l}\text { PLG } \\
(\mathrm{n}=20)\end{array}$ \\
\hline Age, years & $50 \pm 14$ & $52 \pm 11$ \\
Females/males & $10 / 5$ & $8 / 7$ \\
Right/left & $12 / 3$ & $12 / 3$ \\
Dominant/non-dominant side & $9 / 6$ & $10 / 5$ \\
Working/sedentary & $11 / 4$ & $13 / 2$ \\
SIS (100 maximally), \% & $37 \pm 18$ & $39 \pm 14$ \\
\hline
\end{tabular}

to determine passive and active range of motion, which was defined as forward elevation, external rotation, external rotation with arm at $90^{\circ}$ abduction, internal rotation noting the highest point of the spinal anatomy, and cross body adduction. The patient was asked to identify whether he or she experienced symptoms of instability. The sensation of instability was assessed quantitatively according to a VAS. A higher score was given when the shoulder felt very unstable.

\section{Statistical Methods}

Study data were collected on customized case report forms and entered into a computerized database that allowed unbiased and reliable data management. Statistical analysis utilized SAS ${ }^{\circledR}$ statistical software (SAS Institute, Cary, N.C., USA, 2003). Categorical data were expressed as percentages with all 40 patients included. Measured data were expressed as means \pm SD.

Univariate analysis was performed by means of Fisher's exact test on all categorical data and Student's test on all measured data. Differences between means were analyzed using Student's $t$ test and Satterthwaite's approximation which does not assume equal variances and provides a more conservative test of significance than the standard t test [14]. A two-sided $\mathrm{p} \leq 0.05$ was considered to be statistically significant.
Table 3. Use of pain medication after OSD

\begin{tabular}{|c|c|c|c|c|}
\hline & \multicolumn{2}{|c|}{ Control $(\mathrm{n}=20)$} & \multicolumn{2}{|c|}{ PLG $(\mathrm{n}=20)$} \\
\hline & $\begin{array}{l}\text { regular/ } \\
\text { strong }\end{array}$ & $\begin{array}{l}\text { mean } \\
\text { (range) }\end{array}$ & $\begin{array}{l}\text { regular/ } \\
\text { strong }\end{array}$ & $\begin{array}{l}\text { mean } \\
\text { (range) }\end{array}$ \\
\hline Preoperatively & $6 / 3$ & $1.8(0-6)$ & $5 / 2$ & $1.2(0-5)$ \\
\hline \multicolumn{5}{|l|}{ Postoperatively } \\
\hline 1 week & $5 / 5$ & $2.7(0-6)$ & $5 / 0^{*}$ & $3.1(0-6)$ \\
\hline 2 weeks & $8 / 2$ & $1.6(0-6)$ & $1 / 0^{*}$ & $0^{*}$ \\
\hline 4 weeks & $2 / 2$ & $0.5(0-2)$ & $1 / 0^{*}$ & $0^{*}$ \\
\hline 6 weeks & $2 / 1$ & $0.4(0-2)$ & 0 & 0 \\
\hline
\end{tabular}

The patients were asked to identify the number of pills they took each day for pain medication, and whether they had taken a regular or strong analgesic. ${ }^{*} \mathrm{p}<0.001$ vs. the control group.

\section{Results}

The baseline characteristics for the two groups are shown in table 2. The groups showed a similar distribution for age and gender, and there were no differences in the duration of symptoms prior to surgery. Also important, the preoperative findings of VAS scores, functional range of motion, and SIS were similar among the two groups. All surgical procedures were uneventful, with no peri- or postoperative complications, and none of the patients received antibiotic treatment for infection. All patient self-assessment forms were returned to the investigator and all patients completed the follow-up period.

\section{Platelet and Leukocyte Counts}

Platelet and leukocyte counts were assessed with a fully automated analyzer (Cell-Dyn ${ }^{\mathrm{TM}} 4000$, Abbott Diagnostics, Santa Clara, Calif., USA), using a combination of optical and impedance methods for all blood samples. The preoperative whole blood platelet count of PLGtreated patients after MAPS centrifugation increased from $206 \pm 42$ to $1,183 \pm 396 \times 10^{9} / 1$ in the P-LRP, a 5.7 -fold increase from baseline $(\mathrm{p}<0.001)$. The preoperative leukocyte count increased 2.7-fold compared to the leukocyte count in the P-LRP $(4.8 \pm 1.3$ and $13.0 \pm 2.8$, respectively; $\mathrm{p}<0.001)$.

\section{Pain and SIS}

In the PLG-treated patients, a decrease in the VAS pain score was observed compared to the non-treated patients ( $p<0.001$; fig. 2). After 3 months of follow-up, pain decreased markedly in both groups. The PLG-treated patients used significantly less pain medication, with only 
Table 4. Self-evaluation instability score in patients treated with OSD

\begin{tabular}{|c|c|c|c|c|}
\hline & \multicolumn{2}{|c|}{ Control $(\mathrm{n}=20)$} & \multicolumn{2}{|c|}{ PLG $(n=20)$} \\
\hline & yes/no & instable score & yes/no & instable score \\
\hline Preoperatively & $4 / 11$ & $3.7 \pm 2.9(0-9)$ & $5 / 10$ & $3.3 \pm 2.7(0-8)$ \\
\hline \multicolumn{5}{|c|}{ Postoperativley } \\
\hline 1 week & $4 / 11$ & $2.9 \pm 2.6(0-8)$ & $3 / 12$ & $1.8 \pm 2.1(0-8)$ \\
\hline 2 weeks & $3 / 12$ & $1.6 \pm 1.6(0-6)$ & $2 / 13$ & $1.4 \pm 0.6(0-3)$ \\
\hline 4 weeks & $3 / 12$ & $2.1 \pm 1.9(0-6)$ & $2 / 13$ & $1.7 \pm 0.9(0-4)$ \\
\hline 6 weeks & $2 / 13$ & $2.0 \pm 2.0(0-6)$ & $1 / 14$ & $1.1 \pm 0.3(0-2)$ \\
\hline
\end{tabular}

1 patient using regular pain medication until the end of the 2 nd week $(p<0.001)$. Ten control group patients were on regular or heavy pain medication during this period and continued using pain medication until 6 weeks postoperatively (table 3 ). The SIS was significantly better during the postoperative period for patients treated with PLG ( $p<0.001$; fig. 3). At the end of the follow-up period, a satisfying SIS was achieved in both groups. The control group improved 35\% and the PLG-treated patients improved $47 \%$ compared to the preoperative SIS measurements, respectively. Six weeks postoperatively, the VAS scores of the control and treatment groups were $2.0 \pm 2.0$ and $1.1 \pm 0.3$, respectively.

\section{Instability}

The patient self-assessment score for instability showed no significant difference between both groups (table 4). During the postoperative period, patients in the PLGtreated group experienced slightly less shoulder instability. However, the physician instability scores did not show differences between both groups ( $\mathrm{p}=0.13)$; the difference in the number of patients not experiencing instability was 1 patient less in the PLG group. In treated patients, the instability score was not significantly better compared to control patients $(\mathrm{p}=0.13)$.

\section{Activities of Daily Living}

PLG-treated patients were able to perform more activities listed on the ADL questionnaire 2 weeks postoperatively $(\mathrm{p}<0.05)$ and they continued to perform better than the control patients, until 6 weeks postoperatively. Four weeks after surgery, PLG-treated patients were able to increase ADL performance and to sleep on the operated shoulder $(p<0.05)$. Patients in the treatment group were able to return to work earlier than did control patients.

Application of PLG during Open

Subacromial Decompression

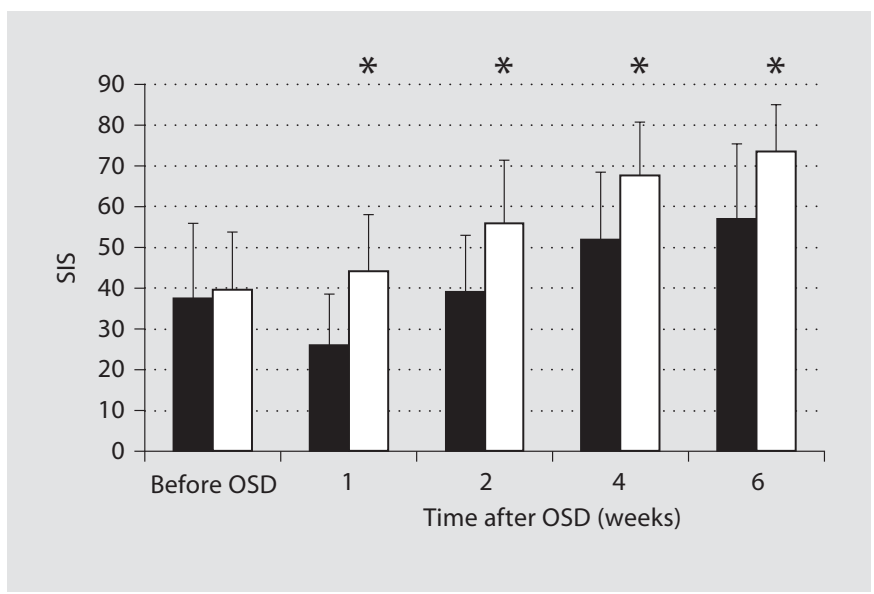

Fig. 3. SIS score up to 6 weeks postoperatively of the control ( and PLG-treated patients $(\square) .{ }^{*} \mathrm{p}<0.001$ vs. the control group.

\section{Range of Motion}

Two weeks postoperatively, PLG-treated patients significantly improved passive forward elevation $(\mathrm{p}<0.001)$, external rotation, external rotation with arm at $90^{\circ} \mathrm{ab}-$ duction, internal rotation, and cross body adduction compared to control patients. Four and 6 weeks after surgery, PLG-treated patients still performed better than control patients, who tended to 'catch up' 3 months postoperatively (fig. 4-7).

\section{Discussion}

Shoulder impingement is a common disorder and OSD has proven useful where conservative, non-operative therapies failed. The results of a well-performed acromioplasty are dependent on the time of postoperative rehabilitation. We have studied the outcome of OSD in combination with the application of PLG at the end of the surgical procedure. PLG is prepared from autologous whole blood donated before surgery and can be applied locally at the wound site to enhance soft tissue regeneration. The rationale to use PLG is the high contents of platelets, leukocytes, and thrombin. PLG forms a source of grow th factors, which are already present in vivo, at tissue wound sites [15-17]. PLG has been used successfully to support wound healing [18], control bleeding [6], promote bone growth [19], and reduce infections [20]. After a surgical incision, tissue repair begins with platelet plug formation, activation of the coagulation cascade, and platelet degranulation. Platelet degranulation results in the release of

Eur Surg Res 2008;40:203-210 

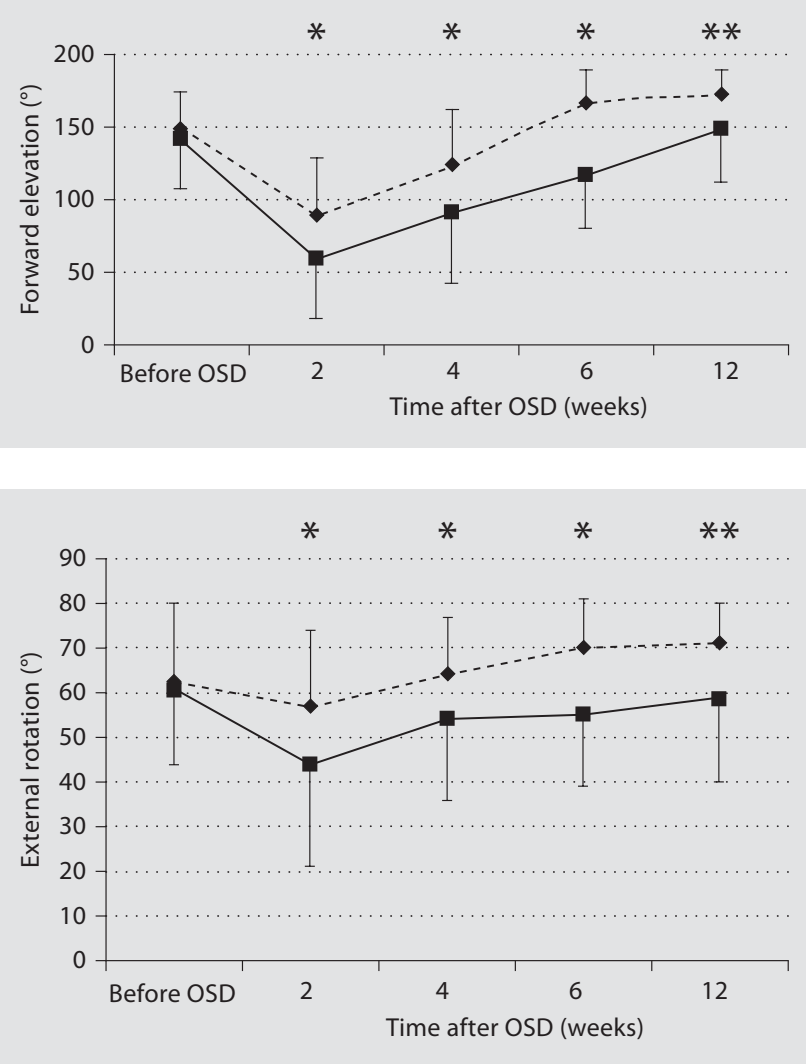

5
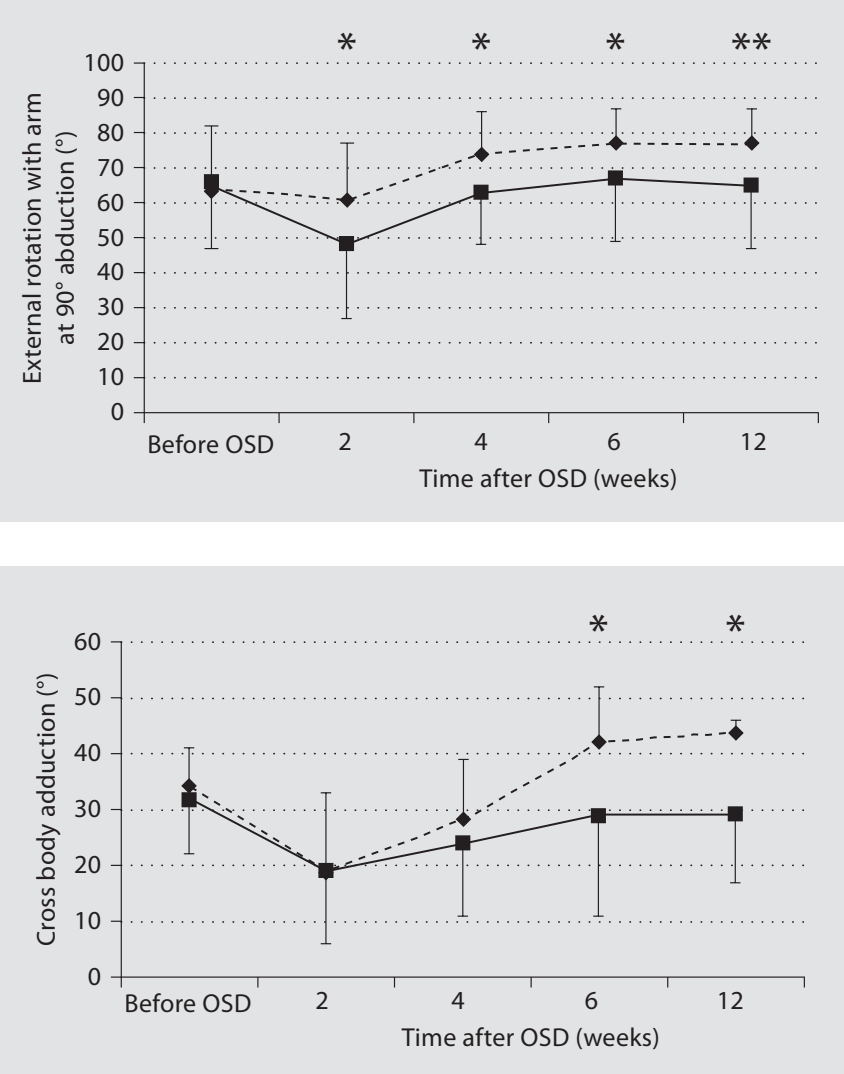

platelet growth factors, including TGF- $\alpha$ and $-\beta$, PDGF strain $\mathrm{AB}$, fibroblast growth factor, and epidermal growth factor [21]. During the different stages of wound healing, these specific platelet growth factors regulate processes involved in cell-cell and cell-matrix interactions required for wound healing. Various studies show the benefit of autologous PLG application. Platelet growth factors can work synergistically, promoting mitogenesis of mesenchymal stem cells at the wound site [22-24]. In this study, patients treated with PLG had a more successful rehabilitation, with an earlier recovery of shoulder function. This was not solely due to less pain. The external/internal rotation movement pattern was significantly better in treated patients, and this pattern is only weakly correlated to pain, as indicated by Holm et al. [25]. Therefore, we propose that a high concentration of PDGF at the surgical wound site improves tissue healing, resulting in an improved shoulder function with an earlier return of ADL. A drawback of this study is that patients were only followed up for 3 months. Thus, it is not known at what point in time the non-treated patients were able to perform the same activities as the PLG-treated patients.

In a wound treatment study by Crovetti et al. [7], a reduction in pain sensation was observed when PLG was applied, but they offered no explanation for these observations. In our study, the application of PLG resulted in less postoperative pain, decreased usage of pain medication, and a quicker recovery of shoulder function. Santavirta et al. [26] studied shoulder pain originating from the subacromial bursa. They performed an immunohistochemical study in patients treated with OSD and demonstrated that immunoreactive sensory afferent fibers arise in the subacromial bursa. Interestingly, Sprott et al. [27] reported on pain reduction following acupuncture and measured a decrease in serotonin (5-HT) concentration in platelets from these patients and an increase in 5-HT levels in plasma, suggesting normalization of plasma 5-HT levels due to the mobilization of platelet 5-HT. We also showed pain reduction after treatment with PLG, which might be the result of PLG application. Except for the $\alpha$ granules, platelets also contain dense granules, which hold large amounts of 5-HT [28]. Since the platelet counts were almost sixfold higher in the PLG, 5-HT might have

Fig. 4-7. Degrees of forward elevation (4), external rotation (5), external rotation with arm at $90^{\circ}$ abduction (6) and cross body adduction (7) for the control (-) and PLG-treated patients $(---) .{ }^{*} \mathrm{p}<0.001,{ }^{* *} \mathrm{p}<0.05$ vs. the control group. 
been released at the wound site following platelet activation. Also, a chronic inflammatory reaction has been demonstrated [29], resulting in the activation of nociceptors. These patients develop serious pain complaints [30]. Blaine et al. [31] proposed to use anti-inflammatory agents for the treatment of subacromial impingement, in order to reduce inflammation. In this regard, we postulate an additional effect of PLG when applied to inflammatory tissues, since we demonstrated that except for a high concentration of platelets, high concentrations of viable leukocytes are present, in particular neutrophils and monocytes [10]. In addition, platelet growth factors initiate macrophage migration [4]. Bielecki et al. [32] demonstrated in an in vitro study an antibacterial effect of autologous PLG. Furthermore, Tang et al. [33] demonstrated that platelets also have antimicrobial properties, as they contain multiple antimicrobial peptides.

Pain is an important symptom in patients with impingement syndrome. Both treated and non-treated patients experienced the same pain sensation and therefore there was no statistical difference between the two groups before surgery. Postoperatively, the self-assessments showed that the ASES shoulder scores and range of motion were significantly improved in PLG-treated patients, experiencing less pain. The control group did not show the same clinical results as did the treated group, even after 3 months of rehabilitation. The impaired range of motion and increased sensation of shoulder pain could not be explained by baseline differences between the two groups or tears of the rotator cuff which did not occur. Furthermore, the earlier functional recovery of PLGtreated patients was not hindered by surgery of the nondominant shoulder, as stated by Patel et al. [34], since we had an even distribution of dominant and non-dominant shoulders being operated on in our study. No side effects were noticed in patients who were treated with PLG. None of the treated patients demonstrated signs of inflammation as a result of their PLG injections when compared to the non-treated patients (no differences in C-reactive protein measurements between the two patient groups were seen, data not shown). Furthermore, PLGtreated patients did not experience an increased incidence of arthrofibrosis at postoperative evaluations. This is in accordance with results recently published by our group in patients in whom PLG was injected intracapsularly after total knee replacement [35]. Nonetheless, in these PLG-treated patients, a significantly decreased incidence of arthrofibrosis was observed.

In conclusion, this is the first prospective, randomized, blinded study using subacromial-applied PLG in OSD surgery. We demonstrated that the use of PLG in OSD is very effective for regaining early shoulder function with better control of postoperative pain. Future studies are warranted to elucidate the long-term effects of PLG application on shoulder function, and to clarify the role of platelets and leukocytes as anti-inflammatory agents of PLG.

\section{Acknowledgments}

The authors would like to thank Mr. H. Box and Mr. E. Overdevest for their support of this study. We are also grateful to Ms. S. Westelaken and M. Sahin for the patient record administration, Ms. K. van Erp for proofreading and DL Graphics for the illustrations.

\section{References}

1 Hawkins RJ, Abrams JS: Impingement syndrome in the absence of rotator cuff tear (stages 1 and 2). Orthop Clin North Am 1987; 18:373-382.

$\checkmark 2$ Husby T, Haugstvedt JR, Brandt M, Hom I, Stenn H: Open versus arthroscopic subacromial decompression. A prospective randomized study of 34 patients followed for 8 years. Acta Orthop Scand 2003;74:408-414.

3 Neer CS II: Anterior acromioplasty for the chronic impingement syndrome in the shoulder: a preliminary report. J Bone Joint Surg Am 1972;54A:41-50. $\checkmark 4$ Mustoe TA, Pierce GF, Thomason A, Gramates P, Sporn MB, Deuel TF: Accelerated healing of incisional wounds in rats induced by transforming growth factor- $\beta$. Science 1987;237:1333-1336.

5 Pierce GF, Mustoe TA, Lingelbach J, Masakowski VR, Griffin GL, Senior RM, Deuel TF: Platelet-derived growth factor and transforming growth factor $\beta$ enhance tissue repair activities by unique mechanisms. J Cell Biol 1989;109:429-440.

6 Everts PA, Devilee RJ, Brown Mahoney C, Eeftinck-Schattenkerk M, Box HA, Knape JT, van Zundert A: Platelet gel and fibrin sealant reduce allogeneic blood transfusions in total knee arthroplasty. Acta Anaesthesiol Scand 2006;50:593-599.
7 Crovetti G, Martinelli G, Issi M, Barone M, Guizzardi M, Campanati B, Moroni M, Carabelli A: Platelet gel for healing cutaneous chronic wounds. Transfus Apher Sci 2004;30:145-151

$\checkmark 8$ Henderson JL, Cupp CL, Ross EV, Shick PC, Keefe MA, Wester DC, Hannon T, McConnell D: The effects of autologous platelet gel on wound healing. Ear Nose Throat J 2003; 82:598-602.

$\checkmark 9$ Everts PA, Hoffmann J, Weibrich G, Mahoney CB, Schönberger JP, van Zundert A, Knappe BT: Differences in platelet growth factor release and leucocyte kinetics during autologous platelet gel formation. Transfus Med 2006; 16:363-368. 
10 Everts PA, Jakimowicz JJ, van Beek M, Schönberger JP, Devilee RJ, Overdevest EP, Knape JTA, van Zundert A: Reviewing the structural features of autologous plateletleukocyte gel and suggestions for use in surgery. Eur Surg Res 2007;39:199-207.

11 Richards RR, An KN, Bigliani LU, Friedman RJ, Gartsman GM, Gristina AG, Iannotti JP, Van CM, Sidles JA, Zuckerman JD: A standardized method for the assessment of shoulder function. J Shoulder Elbow Surg 1994;3:347-352.

12 Gartsman GM, Khan M, Hammerman SM: Arthroscopic repair of full-thickness tears of the rotator cuff. J Bone Joint Surg Am 1998; 80:832-840.

-13 Michener LA, McClure PW, Sennett BJ: American Shoulder and Elbow Surgeons Standardized Shoulder Assessment Form, patient self-report section: reliability, validity, and responsiveness. J Shoulder Elbow Surg 2002;11:587-594.

14 Khuri AI, Mathew T, Nel DG: A test to determine closeness of multivariate Satterthwaite's approximation. J Multivariate Anal 1994;51:201-209.

15 Grotendorst GR, Pencev D, Martin GR, Sodek J: Molecular mediators of tissue repair; in Hunt TK, Heppenstall RB, Pines E, Rovee D (eds): Soft and Hard Tissue Repair. New York, Praeger, 1984, pp 20-40.

- 16 Lucarelli E, Beccheroni A, Donati D, Sangiorgi L, Cenacchi A, Del Vento AM, Meotti C, Bertoja AZ, Giardino R, Fornasari PM, Mercuri M, Picci P: Platelet-derived growth factors enhance proliferation of human stromal stem cells. Biomaterials 2003;24:30953100.

17 Robson MC: Growth factors as wound healing agents. Curr Opion Biotechnol 1991;2: 863-867.
8 Mazzucco L, Medici D, Serra M, Panizza R, Rivara G, Orecchia S, Libener R, Cattana E, Levis A, Betta PG, Borzini P: The use of autologous platelet gel to treat difficult-to-heal wounds: a pilot study. Transfusion 2004;44: 1013-1018.

19 Dallari D, Fini M, Stagni C, Torricelli P, Nicoli Aldini N, Giavaresi G, Cenni E, Baldini N, Cenacchi A, Bassi A, Giardino R, Fornasari PM, Giunti A: In vivo study on the healing of bone defects treated with bone marrow stromal cells, platelet-rich plasma, and freeze-dried bone allografts, alone and in combination. J Orthop Res 2006;24:877888.

20 Trowbridge CC, Stammers AH, Woods E, Yen BR, Klayman M: Use of platelet gel and its effects on infection in cardiac surgery. J Extra Corpor Technol 2005;37:381-386.

21 McGrath MH: Peptide growth factors and wound healing. Clin Plast Surg 1990;17:421432.

22 Brown RL, Breeden MP, Greenhalg DG: PDGF and TGF-alpha act synergistically to improve wound healing in the genetically diabetic mouse. J Surg Res 1994;56:562570 .

23 Hunt TK: Basic principles of wound healing. J Trauma 1990;30:S122-S128.

24 Kells AF, Coats SR, Schwartz HS, Hoover RL: TGF-beta and PDGF act synergistically in affecting the growth of human osteoblastenriched cultures. Connect Tissue Res 1995; 31:117-124.

25 Holm I, Brox JI, Ludvigsen P, Steen H: External rotation - best isokinetic movement patterns for evaluation of muscle function in rotator tendinosis. A prospective study with a 2-year follow-up. Isokinet Exerc Sci 1996;5: 121-125.

26 Santavirta S, Gronblad M, Antti-Poika I, Konttinen YT, Polak JM: Protein gene product 9.5, synaptophysin- and neuropeptideimmunoreactive nerves in human subacromial bursal tissue. Eur J Exp Musculoskel Res 1993;2:93-99.
7 Sprott H, Franke S, Kluge H, Hein G: Pain treatment of fibromyalgia by acupuncture. Rheumatol Int 1998;18:35-36.

28 Vanhoutte PM: Platelet-derived serotonin, the endothelium, and cardiovascular disease. J Cardiovasc Pharmacol 1991;17S:S6S12.

29 Santavira S, Konttinen YT, Antti-Poika I, Nordstrom D: Inflammation of the subacromial bursa in chronic shoulder pain. Arch Orthop Trauma Surg 1992;111:336-340.

30 Grigg P, Schaible HG, Schmidt RF: Mechanical sensitivity of group III and IV afferents from the posterior articular nerve in normal and inflamed cat knee. J Neurophysiol 1986; 55:653-643.

31 Blaine TA, Kim YS, Voloshin I, Chen D, Murakami K, Chang SS, Winchester R, Lee FY, O'keefe RJ, Bigliani LU: The molecular pathophysiology of subacromial bursitis in rotator cuff disease. J Shoulder Elbow Surg 2005; 14:84S-89S

32 Bielecki TM, Gazdzik TS, Arendt J, Szczepanski T, Król W, Wielkoszynski T: Antibacterial effect of autologous platelet gel enriched with growth factors and other active substances: An in vitro study. J Bone Joint Surg Br 2007;89:417-420.

33 Tang YQ, Yeaman MR, Selsted ME: Antimicrobial peptides from human platelets. Infect Immun 2002;70:6524-6533.

34 Patel VR, Singh D, Calvert PT, Bayley JI: Arthroscopic subacromial decompression: results and factors affecting outcome J Shoulder Elbow Surg 1999;8:231-237.

35 Everts PA, Devilee RJ, Oosterbos CJ, Mahoney CB, Schattenkerk ME, Knape JT, van Zundert A: Autologous platelet gel and fibrin sealant enhance the efficacy of total knee arthroplasty: improved range of motion, decreased length of stay and a reduced incidence of arthrofibrosis. Knee Surg Sports Traumatol Arthrosc 2007;15:888-894. 